TECHNICAL NOTE:

\title{
STRONG-MOTION INSTRUMENTATION AND RECORDS IN THE WANGANUI EARTHOUAKE SWARM
}

\author{
G H McVerry* and R T Hefford*
}

Advice was received from the seismological observatory in the afternoon of Thursday, October 14, 1982 that the earthquake swarm felt in Wanganui over the previous few days was the strongest activity in the area for many years and that it would be worthwhile to have strongmotion instrumentation in the area. The only PEL instrument in Wanganui at that time was a scratch-plate in the basement of the Post Office, with the nearest film-recording MO2 accelerographs 25 kilometres from Wanganui in the fourinstrument array at Atene on the Wanganui River. There were, however, two sixcomponent Solid State Equipment (SSE) Ltd digital accelerographs located in an office building in Wanganui. No earthquakes had been recorded on a SEE accelerograph previously. It was therefore decided to install a $\mathrm{MO} 2$ in Wanganui and another at some suitable site to be determined after discussion with the Seismological observatory team monitoring the swarm.

The team from the Engineering Seismology Section of PEL arrived in Wanganui on Saturday, October 16, the delay being caused by the necessity to recall the technicians with the servicing equipment and one of the accelerographs from a network maintenance trip in the East Cape area. The team from the Engineering Seismology Section of PEL arrived in Wanganui on Saturday, October 16, the delay being caused by the necessity to recall the technicians with the servicing equipment and one of the accelerographs from a network maintenance trip in the East Cape area. The first instrument was installed on a concrete slab in a light-weight bicycle shelter at Wanganui Police Station, becoming operational at $1.29 \mathrm{pm}$. Later that afternoon it was learned that the swarm was centred about $30 \mathrm{~km}$ off the coast between Wanganui and Bulls, so it was decided to place the second instrument near Bulls. This installation was completed by 9.30 am on the Sunday, with the site being on a substantial concrete floor in a disused portion of a singlestorey masonry building housing a generator at the RNZAF transmitter station approximately 3 kilometres east of ohakea.

After that, the array at Atene was visited. All instruments were operational but only one had triggered. The record from this ridge-top instrument, while of small acceleration ( $0.025 \mathrm{~g}$ or less), is clearly discernible for approximately twenty seconds. New films were placed in all instruments. Servicing of the instru-

*Engineering Seismology Division, Physics and Engineering Laboratory, D.S.I.R., Gracefield, Lower Hutt. ments in the Wanganui area was completed by retrieving the scratch-plate slide from the Post office. The scratch-plate and early Mol-type accelerograph at Palmerston North were inspected on the trip back to PEL. Neither of these instruments had recorded.

The scratch-plate record from Wanganui shows a peak acceleration of less that $0.03 \mathrm{~g}$. A much larger scratch-plate record, $0.12 \mathrm{~g}$, was recovered from Napier earlier in the trip, not surprising considering that the september 3, 1982 Napier earthquake was magnitude 5.8 centred under Flaxmere, only a few kilometres from Napier, while the largest shallow event in the Wanganui swarm has been magnitude 5.3 , centred about $30 \mathrm{~km}$ out to sea from the city. Records of the Napier earthquake from several other sites in Hawkes Bay exceed the Wanganui record. The records from Wanganui and Napier are shown for comparison (Figures 1 and 2 respectively).

The SSE digital recorders triggered during the magnitude 5 event of $11.25 \mathrm{am}$ Thursday, October 14. This event also disrupted the Wanganui power supply by tripping the isolation relays on the transformers. The peak basement acceleration was $0.013 \mathrm{~g}$, and the maximum response recorded in the lift-room at the top of the six-storey building just under $0.03 \mathrm{~g}$. A 0.2 second period motion was apparent in the acceleration histories at both the second floor and roof levels, with a nearly pure sinusoid of this period with a roof amplitude of $0.015 \mathrm{~g}$ set up for several cycles. The peaks of the Fourier acceleration spectra at the second floor and roof were at this period, which from the height of the building is possibly the second mode.

These levels of vibration can be accommodated comfortably within the elastic range by engineered structures. No significant structural damage is evident in the area. Much stronger motion has been recorded this year, for example $0.09 \mathrm{~g}$ roof response in the Gisborne Post Office from the magnitude 5.5 event of March 4, 1982. The recently recovered scratch-plate records from Hawkes Bay also substantially exceed the Wanganui accelerations. Although the earthquake swarm at Wanganui has produced widespread alarm as far south as Wellington, probably the main cause of apprehension is the fact that there has been a succession of felt shocks, which has made the public fear that they are the forerunners of a larger event.

With activity still continuing in the Wanganui area, the two instruments installed at Wanganui and Ohakea should stay in place for several months at least. This area was an obvious gap in the network and at least one of these sites should be permanent. However the present two instruments were not spare, but rather were about to be re-installed in dedicated sites after maintenance. This event draws attention to the need to locate recording instruments permanently in this area. 


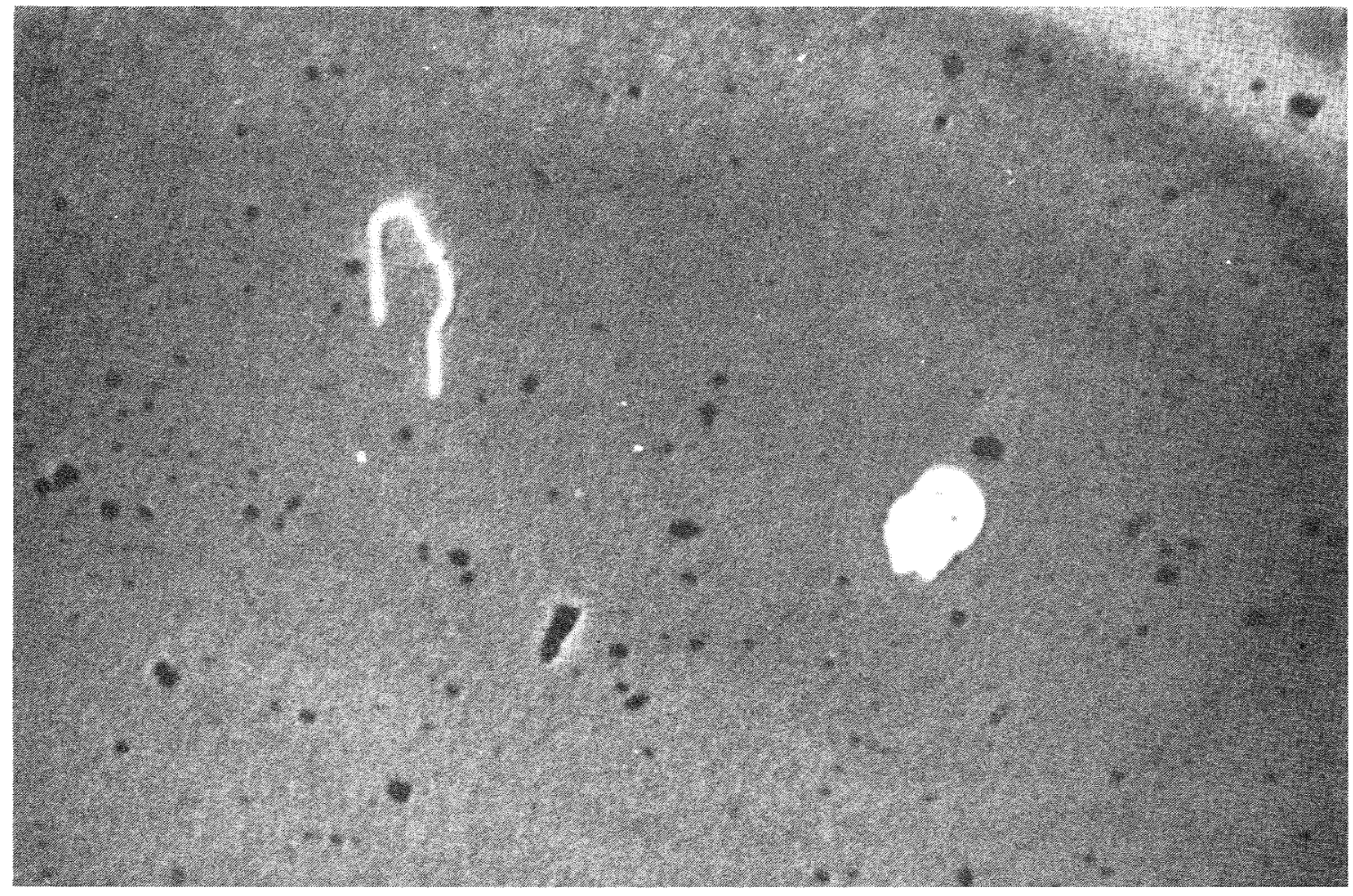

FIG. 1 Scratch plate acceleration record from the Wanganui swarm of earthquakes of October 1982 (maximum acceleration recorded $0.035 \mathrm{~g}$ ).

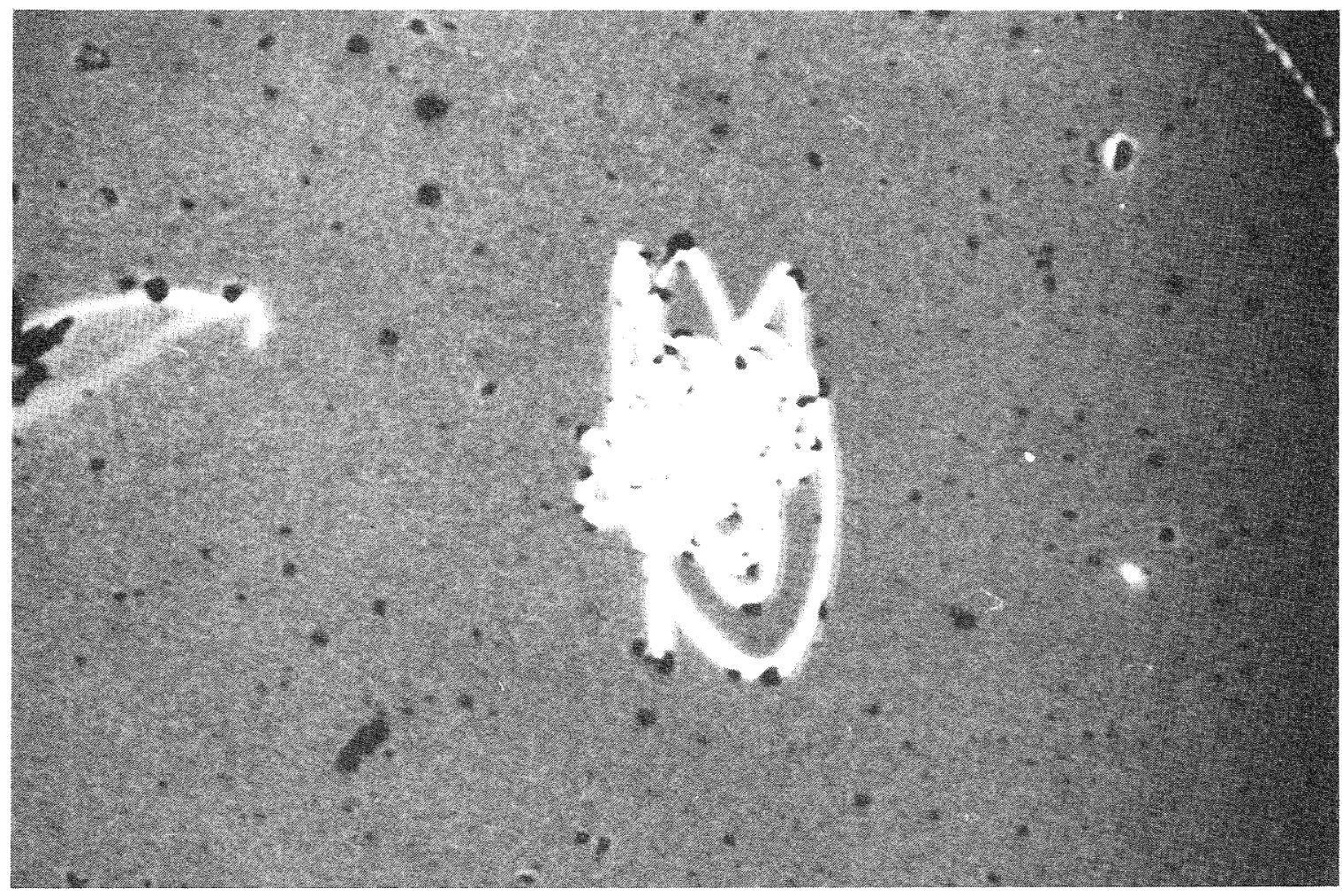

FIG. 2 Scratch plate acceleration record from September 3, 1982 Napier earthquake (maximum recorded acceleration $0.12 \mathrm{~g}$ ). 